\title{
THE INCIDENCE AND RISK FACTORS OF BRAIN INJURY IN MULTIPLE PREGNANCY PRETERM INFANTS
}

\author{
X.L. Bai, Y.H. Cao \\ Paediatrics Department, General Hospital of Jinan Military Command, Jinan, China
}

Background: Preterm infants have been shown to be prone to brain damage, which affect their future quality of life.

Objective: The retrospective study is to evaluate the incidence and the risk factors of brain injury for multiple pregnancy preterm infants.

Methods: 72 multiple pregnancy preterm infants and 99 single pregnancy preterm infants (28-35 wk of gestational age and $600-2410 \mathrm{~g}$ of weight at birth) were studied. The incidence and risk factors of brain injury were analyzed by way of multiple regression analyses.

Results: Compared with single pregnancy preterm infants, multiple pregnancy preterm infants had higher incidence rate of brain injuries $(32 / 72$ vs $27 / 99, \mathrm{P}<0.01)$, The more of the pregnancy number, the less of the infants weight, the less of gestational age, the higher of the brain injuries incidence rate. For infants at gestational age $\leq 30$ weeks, the brain injury incidence rate was higher than single pregnancy preterm infants $(67.9 \%$ vs $43.6 \%)$. The group of weight $\leq 1500 \mathrm{~g}$ had higher incidence rate of brain injury. There's no difference between groups of multiple pregnancy preterm infants and single pregnancy preterm infants. The main risk factors are pregnancy-induced hypertension syndrome, asphyxia, fetal distress, amniotic fluid meconium III degree pollution, NRDS, frequent breath stops, hypoglycemia, neonatal hyperbilirubinemia.

Conclusion: The preterm brain injuries occur more often in multiple pregnancy preterm infants, which were related to many factors. 